\title{
Successes and Challenges in the Implementation and Running of the First ME-Practice Class in the 2nd Undergraduate Year as Part of a Curriculum Revision
}

\section{Dr. Paul J. van Susante, Michigan Technological University}

Dr. van Susante is a senior lecturer at Michigan Technological University. He received his BSc and MSc in Civil Engineering from Delft University of Technology followed by a MSc and $\mathrm{PhD}$ in Engineering Systems (Civil, Mechanical and Electrical Engineering hybrid) from the Colorado School of Mines. He started at Michigan Technological University in Fall 2012 as a lecturer in Mechanical Engineering and has been focused on teaching junior and senior engineering design classes as well as educational and curriculum development. He is coordinator of the first new ME-Practice course in the revised Mechanical Engineering curriculum and faculty advisor of the Mining INnovation Enterprise.

\section{Dr. Nancy B. Barr, Michigan Technological University}

As the Communications and Senior Design Program Advisor, Barr developed a multi-faceted technical communications program in the Mechanical Engineering-Engineering Mechanics Department at MTU. She delivers communication instruction to undergraduate and graduate students, assists faculty in crafting critical thinking/communication assignments, and trains GTAs and faculty in best practices in evaluating student writing. She has a PhD in Rhetoric, Theory, and Culture, with a focus on Writing Program Administration in STEM.

\section{Dr. Jason Blough, Michigan Technological University}

Dr. Blough is an Associate Professor in Mechanical Engineering at Michigan Technological University. Dr. Blough has over 8 years of full time professional experience as well as considerable consulting experience. Dr. Blough's research interests include digital signal processing, dynamic measurements, and noise and vibrations related topics. Dr. Blough has over 80 technical publications on a broad range of topics. Dr. Blough is also the SAE Clean Snowmobile Advisor and SAE Student Chapter Advisor at MTU.

\section{Dr. James P. De Clerck, Michigan Technological University}

After an 18 year career in the automotive industry, Dr. De Clerck joined the Michigan Tech Department of Mechanical Engineering - Engineering Mechanics in August 2009. His areas of expertise include noise and vibration, structural dynamics, design, modal analysis, model validation, inverse methods applied to design, and advanced measurement techniques.

\section{Dr. Michele Miller, Michigan Technological University}

Dr. Michele Miller is a Professor of Mechanical Engineering at Michigan Technological University. She teaches classes on manufacturing and does research in engineering education with particular interest in hands-on ability, lifelong learning, and project-based learning.

Dr. Ibrahim Miskioglu, Michigan Technological University

Prof. Gregory M. Odegard, Michigan Technological University 


\title{
Successes and Challenges in Implementation and Running of the First ME-Practice Class in the 2nd Undergraduate Year as Part of a Curriculum Revision
}

\begin{abstract}
To modernize the curriculum and the skills taught to our Mechanical Engineering students at Michigan Technological University, a curriculum revision process began in 2010, and the first new courses were implemented in fall 2014. The first class has been taught successfully in Fall 2014, Spring, Summer and Fall 2015 semesters. This paper describes the success and challenges in implementation and running of the first of four ME-Practice classes replacing all traditional lab classes as part of a curriculum revision.

The real course content planning started in summer 2013 with the finalization of the detailed definition of learning goals and identification of possible practice session experiments (not labs) that accomplish the learning goals in a particular sequence (scaffolding knowledge). Software packages were chosen and coordinated for use in the curriculum to minimize the students having to learn more software packages than needed. For the two-credit class, 13 weeks of materials were created that cover safety training and writing instruction, data acquisition, reverse engineering of a consumer product and manufacturing techniques, tension and bending testing to determine material properties, multi-domain system modeling software and application in an elevator system test and model validation, introduction to control systems, finite element modeling of truss structures, a bridge experiment, design of a new truss element given engineering requirements and 3D printing and testing of the new truss element, concluding with learning about G-code for lathes and manufacturing of an aluminum chess piece. Supplies were ordered and user manuals as well as practice session instructions were written.

The assignments, quizzes, and practice sessions were then designed to mimic real world scenarios as were weekly deliverables in the form of individual or group reports to a supervisor within the context of the scenario (e.g. you are an engineer working for company $\mathrm{x}$ to reverse engineer a product of company y). The assignments were set up in such a way that each individual student learns each of the skills first, reports on them one week, and then applies them to follow-up assignments in group settings the next week(s). Templates were constructed and grading rubrics implemented to coordinate and standardize all documents and grading. A course template with all documents and assignments was set up in a course management system to facilitate uniform class delivery to all sections.

In Fall 2014, approximately 180 students took the course followed by another 120 in Spring 2015 and 9 in the Summer 2015. In fall 2015, 265 students were enrolled in the class followed by 92 in Spring 2016. The student evaluations and feedback has overall been positive but the logistics have posed challenges related to the volume of students. Most all challenges have been solved, with continuous improvement now the focus of the teaching team. Training teaching assistants and faculty is ongoing to improve uniformity in grading and quality of feedback to the students.
\end{abstract}




\section{Introduction}

As discussed by Miller et al. ${ }^{1}$, the curriculum revision has been planned since 2010 because engineering work, engineering students, and educational methods are changing. The new curriculum content was put together by taking into account recommendations from ASME, the National Academy of Engineering, and the Carnegie Foundation. It also looked at innovative curricula at other institutions and considered the input from departmental faculty and staff during the development process. The goal was to modernize the labs (last updated in 2000), reduce the so called "valley of despair"? in the $2^{\text {nd }}$ and $3^{\text {rd }}$ year, bring in more practice-based engineering education and curricular flexibility as well as introduce powerful computational tools (as opposed to the old calculator-based labs) much earlier and for all students in the curriculum.

There are two components to the curriculum change:

1. It introduces four new practice courses that replace the four traditional lab courses and the Engineering Design Process course in the current curriculum.

2. It reduces the number of core courses and increases the number of technical electives.

The implementation of the new curriculum started in Fall 2014 and each semester a new MEPractice (MEP) course is introduced. MEP-1 in fall 2014, MEP-2 in spring 2015, MEP-3 in fall 2015 and MEP-4 in spring 2016. Starting in fall 2016, a greater number of technical elective classes will be offered. A transition period in which both the old and new curriculum are being taught while the old curriculum is slowly phased out as needed. This transition period is from Fall 2014 to Spring 2017.

Table 1 shows the total credits students had to take to receive their ME degree in the old and new curriculum. In total, 1 credit hour is added to the degree but the changes are taking place in three categories: 2 credits are added for the lab component, the ME core is reduced by 7 credits and 6 credits are added for technical electives. Resulting in the +1 credit hour total.

The 7 credit reduction in core credits comes from combining the original Thermodynamics, Fluid Mechanics and Heat Transfer ( 3 credits each) into two new Energy Thermo Fluids (ETF) 1 \& 2 ( 4 and 3 credits respectively) classes for a reduction of 2 credits, combining Product Realization 1 \& 2 (3 credits each) into a new Mechanical System Design and Analysis (3 credits) class for a reduction of 3 credits and Vibrations and Control Systems class (3 credits each) into one 4 credit Dynamic Systems class for a reduction of 2 credits. The addition of 6 credits of Technical Electives of 4000 level allows the students to specialize more in a specific area of interest.

The four new MEP courses will be integrated with the core courses so the core courses can refer to what was experienced in the MEP courses and the MEP courses explicitly use material from the core courses the students already took or are taking simultaneously. For example, in mechanics of materials (MEEM2150) we can refer to the tension and bending tests. Since the MEP courses are intended to be experiential in nature, the students will experience certain aspects that they will learn more about in future classes. The intent of this linking of core theory classes and the MEP courses is to get the students excited about what the application of theory allows them to do and will allow them to do in future classes, reinforce what they learned by applying it in practice, and possibly reduce the compartmentalization many students apply by immediately forgetting what they learned in a class after the final exam. Instead, this integration of core courses and MEP courses shows that each course builds on the knowledge learned in others and make the connections between the courses in a practical manner. 
Table 1: Credit Distribution in Old (2013) and New Curriculum (2014)

\begin{tabular}{|ll|l|ll|}
\hline Current Curriculum Credits & $\begin{array}{l}\text { Change in } \\
\text { credits }\end{array}$ & New Curriculum Credits \\
\hline 24 & Gen Ed & 0 & 24 & Gen Ed \\
\hline 3 & Econ Decision Analysis & 0 & 3 & Econ Decision Analysis \\
\hline 31 & Math and Science & 0 & 31 & Math and Science \\
\hline 6 & $1^{\text {st }}$ Year Engineering & 0 & 6 & $1^{\text {st }}$ Year Engineering \\
\hline 3 & Free Elective & 0 & 3 & Free Elective \\
\hline 4 & Senior Design & 0 & 4 & Senior Design \\
\hline 5 & ME lab & +2 & 10 & ME-Practice \\
3 & Eng. Des. Process & & & \\
\hline 33 & ME Core & -7 & 26 & ME Core \\
\hline 3 & EE Core & 0 & 3 & EE Core \\
3 & Materials Core & & 3 & Materials Core \\
\hline 9 & Tech Electives & +6 & $\begin{array}{l}15 \\
\text { level) }\end{array}$ \\
\hline $\mathbf{1 2 7}$ & Total (54 ME) & $+\mathbf{1}$ & $\mathbf{1 2 8}$ & Total (55 ME) \\
\hline
\end{tabular}

In addition, the MEP courses build on each other in that software and writing skills learned in the previous course are built upon in the next course. To that end, a common set of software packages was decided upon for use in all MEP courses. This would alleviate the issue that students would learn one software package (e.g. Matlab) and not use it for 3 years until suddenly it was required again for another class, at which time the instructor had to start from scratch. The software packages chosen are Matlab, LMS Amesim, Altair Hyperworks, Microsoft Office, and custom data acquisition executables made in LabView.

This structure does require a more concrete sequence of courses and leads to less freedom to take classes out of sequence due to pre-requisite and co-requisite classes but was deemed necessary to achieve the desired learning outcomes after the MEP course sequence. The big picture themes of the four MEP courses can be found in table 2. The overall course sequence and their relation to other courses is shown in the flow chart shown in Figure 1. An eight-semester long track was created starting with ENG1101 and 1102 which basic skills are prerequisites for MEP-1, then MEP-2, MEP-3 and MEP-4 followed by the two semester Senior Capstone Design sequence. Transfer students typically have to take all four MEP courses since there are no transferrable courses taught elsewhere currently. To avoid the issue of transfer students having to take additional semesters, some MEP courses (currently only MEP-1) are taught in the summer and the pre-requisite between MEP-2 and MEP-3 has been replaced by a co-requisite, making it possible to take MEP-2 and MEP-3 simultaneously (although not encouraged). 


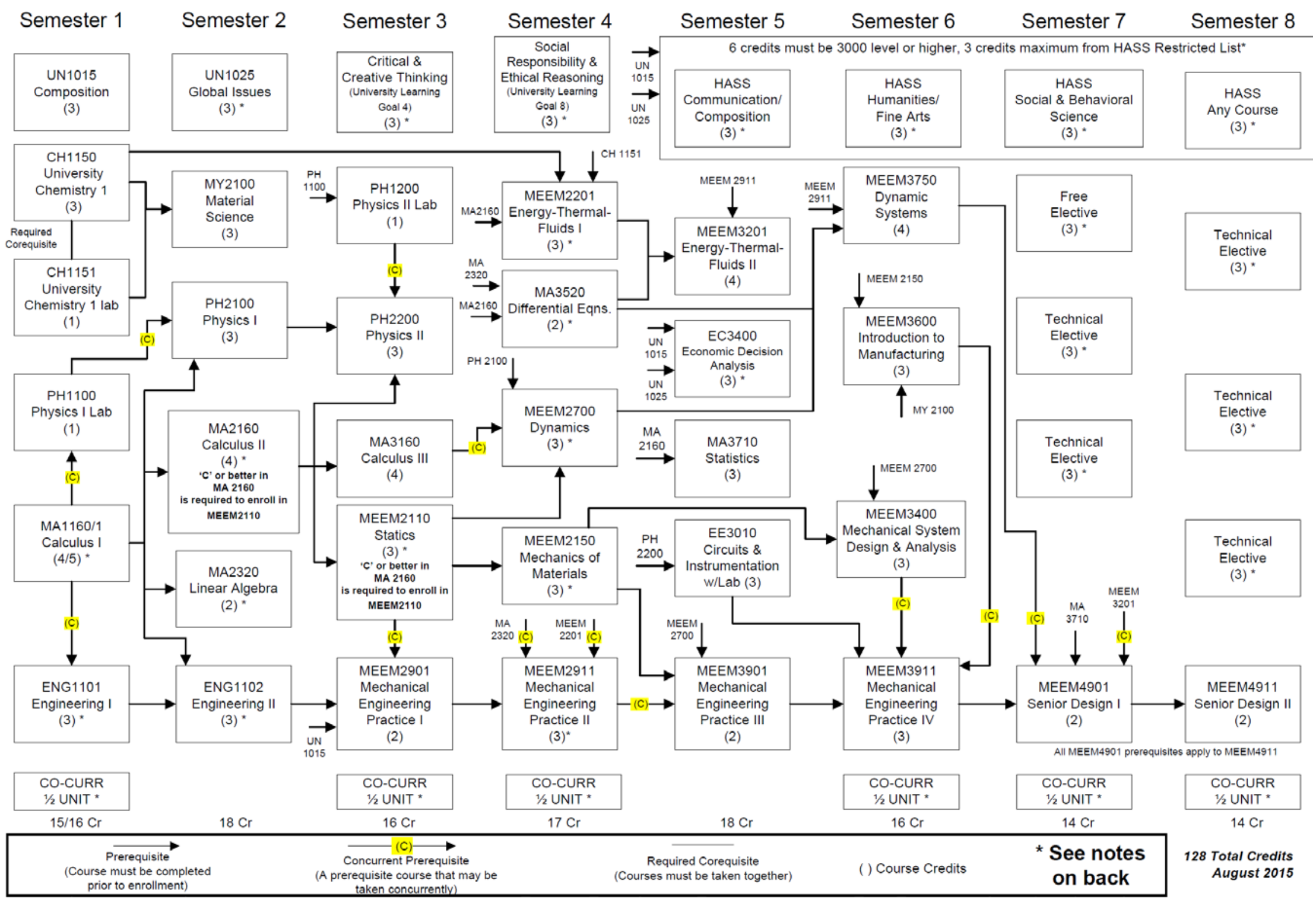

Figure 1: Flowchart for the revised ME-curriculum that started implementation in Fall 2014. 
Table 2: Main themes of the four new MEP courses

\begin{tabular}{|l|l|l|}
\hline \multicolumn{2}{|l|}{ MEP-1 } & MEP-2 \\
\hline & Take things apart, break things & Make things \\
\hline & Develop lab and computer skills & $\begin{array}{l}\text { Conversions between electrical, thermal, } \\
\text { mechanical energy }\end{array}$ \\
\hline Introduction to simulation & Limitations of models \\
\hline & Static situations & Dynamic situations \\
\hline MEP-3 & MEP-4 \\
\hline & Synthesize & Diagnose \\
\hline & System design & Optimize \\
\hline Use evidence based decision making & Innovate \\
\hline & Open ended situations & Control design \\
\hline
\end{tabular}

The remainder of this paper focuses on the first course, MEP-1, its implementation, challenges, and successes.

\section{New learning goals for first course}

As part of the strategy to decrease compartmentalization, we decided to not call the lab component "labs" but practice sessions. Students tend to treat labs as a one-time-and-forget experience that has no connection to lectures, homework, reports, and practical applications on the job. By calling them practice sessions and tying them in with lectures, homework, and multiple weeks of overarching topics based on a scenario, we have tried to make the sessions feel like less of a class and more of a "practice for after you graduate" atmosphere which stresses that the skills and experience will be useful later and reflective of what engineers do after graduation.

A set of learning goals, split into 9 subcategories, was set up for all four courses and distributed/grouped over the courses so it would match with the course content covered and technical skills learned to date. The MEP-1 course takes place in the first semester of the sophomore year and Statics is a pre-requisite or co-requisite, most students take it as a corequisite. The learning goals can be seen in Figure 2. For ABET, the outcomes were defined as following:

a. Specific outcomes of instruction-The student will be able to:

i. Build simple structures with different types of beam cross-sections for various applications

ii. Perform and analyze tension tests for a wide range of materials

iii. Create CAD models of parts and assemblies

iv. Use Matlab to solve engineering problems

$\mathrm{v}$. Understand the uses and limitations of simulation including the need to verify and validate 
vi. Use basic data acquisition systems and apply principles such as sampling, quantization, and aliasing

vii. Acquire high quality data, understanding the concepts of calibration and uncertainty

viii. Select and use appropriate transducers

ix. Evaluate the quality of data and recognize its limitations

x. Create a design that meets a set of requirements

xi. Disassemble a component or system and evaluate design functions and manufacturing processes

xii. Use machine tools and 3D printing systems in the design and build process

xiii. Work safely with equipment and tools

xiv. Draw conclusions and clearly communicate them

\section{New content material development}

Based on the learning goal topics and skill building sequence the 14 week, 2 credit (1hr lecture, 2 hr practice session per week), MEP-1 course was designed to integrate practical hands-on experimentation, theory (equations, analytical solutions), analysis, software tools [CAD, MatLab, AmeSim, Altair Hyperworks (FEA)], and communication. The class is designed with a one-hour lecture and a two-hour practice session. The lecture takes place in a room called the Active Learning Center (ALC) where each student has access to a computer for use during the lecture. The practice sessions take place in four different rooms during the semester depending on what equipment is needed for the session. The students work in teams of three during the practice sessions. The resulting finalized course is structured as follows:

One week of safety training, MatLab refresher and writing instruction

The first lecture starts with the syllabus, a MatLab refresher about importing data, plotting and creating proper plots followed by writing guidelines for the required memos and reports. To start the MEP-1 course, the students receive general safety training consisting of a 30-45 minute safety briefing by the machine shop staff about safe clothing rules, safety glasses, safe conduct, etc., and a 30-minute tour of all the lab rooms for MEP-1 to point out all the safety features of each room (fire extinguisher, medical kit, emergency exit, fire alarm and any other safety features in the room such as eye-wash etc.). Finally, they read and sign a safety statement.

One week of data acquisition

Because most experimental work has a component of data acquisition, students learn about theory and application. Topics covered are components of a data acquisition system (DAQ), sampling frequency related to the frequency of the physical phenomenon to be measured, analog to digital conversion, filtering basics, different transducers, measurement range, etc. During the practice session students use a signal generator and data acquisition system (Figure 3) to experience the effect of a low-pass filter and signal range limitations, calibrate a microphone and use it to measure a known frequency and amplitude from a speaker and finally measure an unknown frequency and amplitude in the form of using the microphone and an electric shaver. They communicate the results in the form of a memo and attached report to their manager, who had asked them to test the data acquisition system for a future project that needed a microphone. 


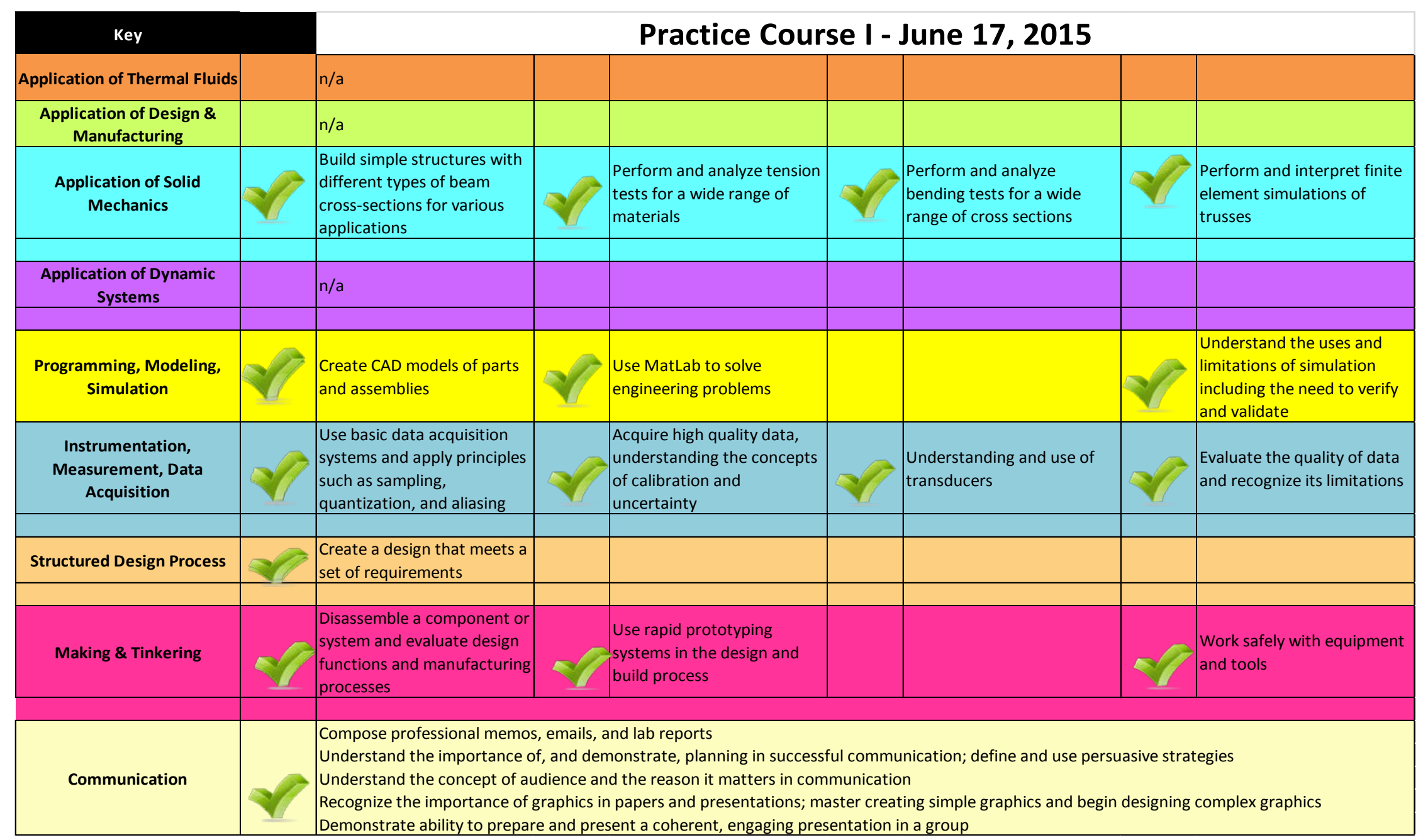

Figure 2: Learning goals for MEP-1, last adjusted June 2015 

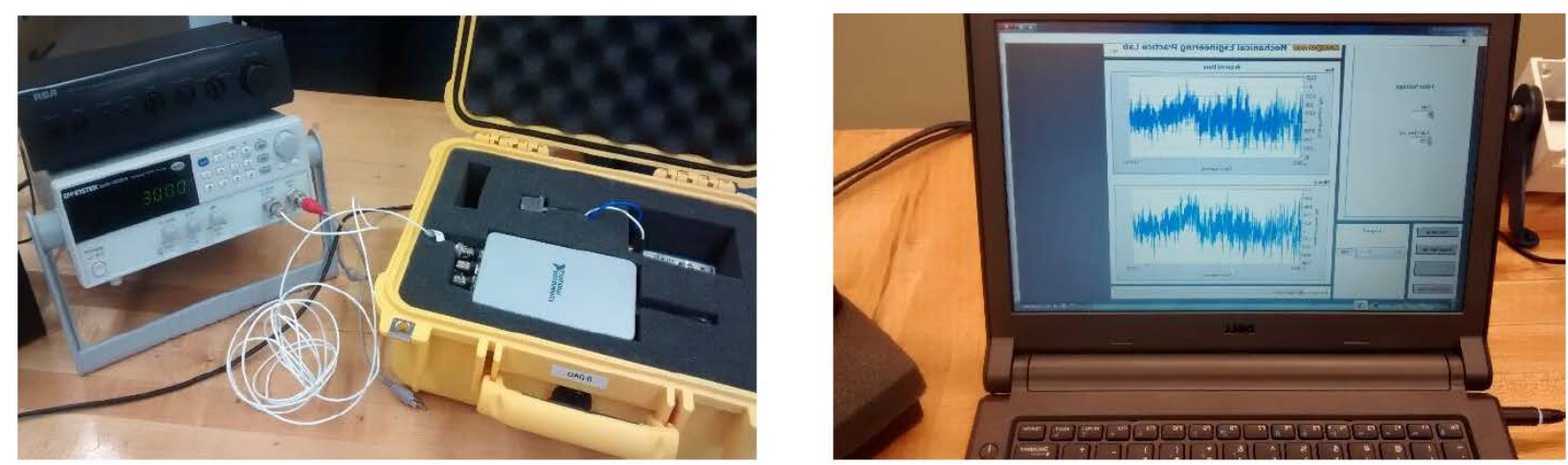

Figure 3: Left, part of the practice session equipment for data acquisition (signal generator, amplifier, NI data acquisition module), right laptop with custom NI interface displaying data.

Two weeks of tension and bending tests

During the lecture, students learn about material properties for ductile and brittle materials, metallic and plastics, standard testing methods (ASTM), forces, displacement, stress and strain as it relates to the tensile test. During the practice session they split up in three teams and each team performs five tensile tests (one each on Steel, Aluminum, Acrylic, Polycarbonate and 3D printed ABS) (Figure 4). This results in 15 sets of data (3 sets for each material) that each individual student has to process using MatLab, plot their stress-strain curves and calculate material properties which they then need to compare to available material properties in the CES Edupak material database. These results then get reported in the form of a memo and attached testing report. For the Bending test, a four-point bending test is performed on the same Tinius Olson universal testing machines that were used for the tensile test. Four aluminum beams with varying cross sectional area and shape are loaded while the deflection is measured in the center. This exercise illustrates the effect of moment of inertia which students have a difficult time to understand without demonstration. The results are compared to the calculated theoretical deflection at the center of the beam and reported in a short memo and attached report.
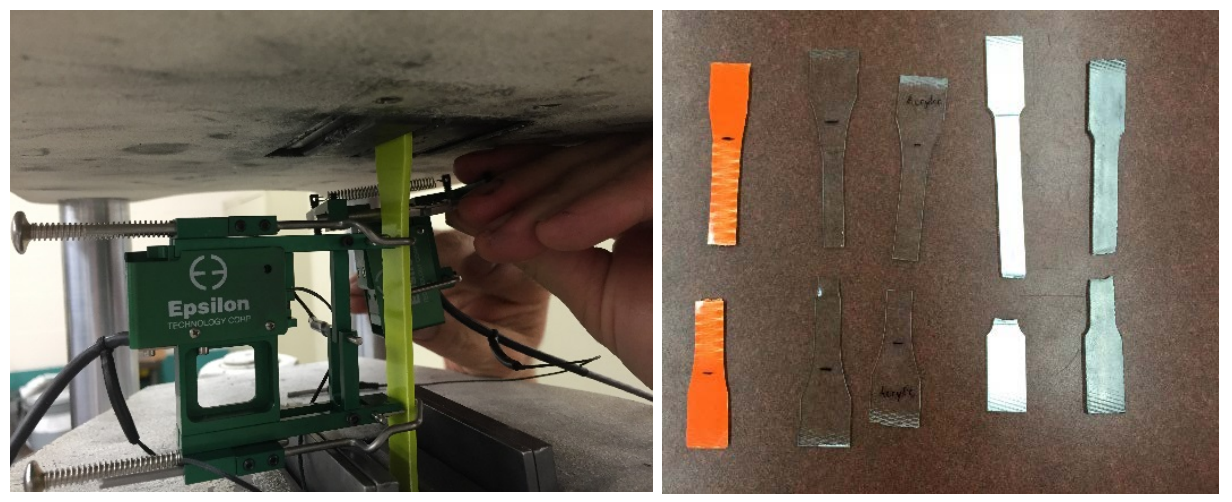

Figure 4: Tinius Olson universal testing machine (Left) when installing the extensometers and the five broken tensile test samples (Right).

Two weeks of reverse engineering

For these two weeks, the scenario is that the students work for consumer reports and have been asked by their manager to study and take apart a consumer product while thinking about customer requirements and needs, functionality, production and manufacturing techniques, and ways to improve the product based on the customer reviews. During the first lecture, the students 
learn about reverse engineering, form follows function, black box models, function structures, customer reviews and engineering requirements. During the second lecture they learn about taking the products apart, manufacturing processes and artifacts, bill of materials, cost of assembly as well as product improvement. The first practice session the students get the product (e.g. a hair dryer, an electric screw driver, a toy submarine, a knitting machine, a blender, etc.), test it, research customer reviews, and hypothesize a function structure of how it works without taking the product apart. During the second practice session, the students take the product apart, make an exploded view (Figure 5), a bill of materials, count and describe the number of assembly operations, find and discuss evidence of manufacturing processes, and discuss how to improve the product. The product improvement portion requires a CAD model of original parts and the improved parts as well as material choices. All this gets reported via memo and a report to the consumer report manager.

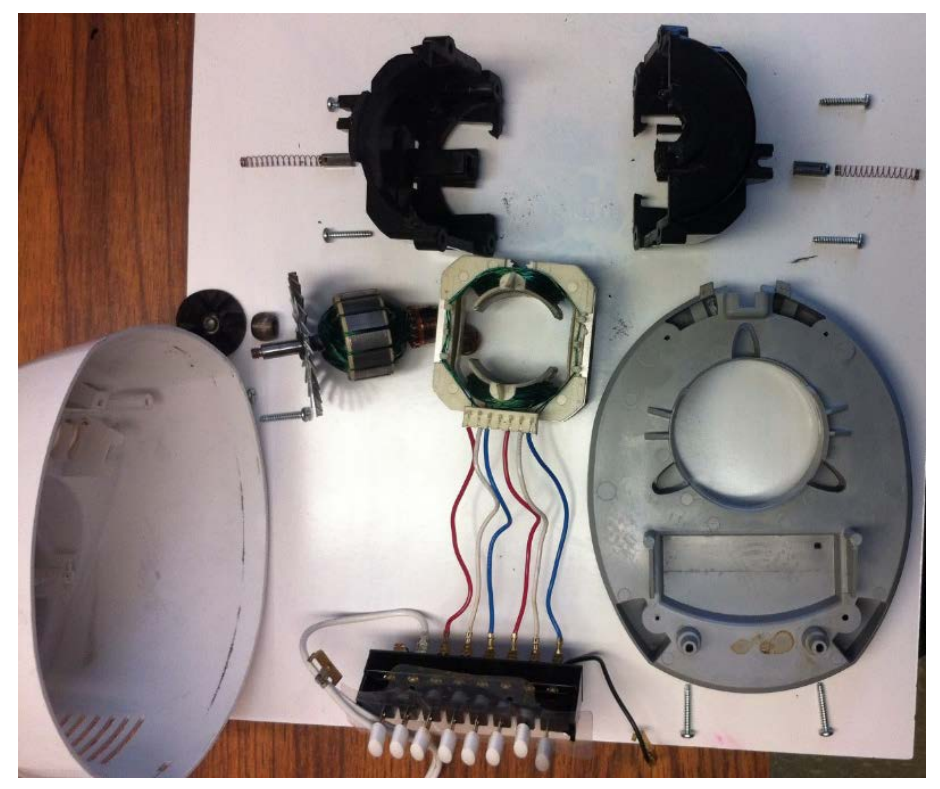

Figure 5: Exploded view of the base of a blender.

Two weeks of the elevator model and experiment

The first week students get a lecture on the LMS AmeSim modeling package and how physical systems can be modeled based on energy and energy conversion between different physical systems. This is illustrated with a simple mass spring test setup. The students then spend the rest of the week doing tutorials to learn the software during which they have to compare model results to an analytical solution and report on the verification of the model in a report to their supervisor in which they have to recommend the use of the AmeSim software for a future project depending on the match of the simulation data and the analytical solution. During the second week, the lecture covers a complex system and its control system (the building's elevators). The model (figure 6) is provided to them, which allows the students to directly experiment with the model and its control system. The model data generated is plotted and explained via the input signal, the measurements and the control system, and error minimization of the PID controller. During the practice session, the students ride the building's elevators and measure the acceleration using accelerometers and compare the results to the provided model in AmeSim software. They have to record the exact trip they made in the elevators (what floors they stopped on and how long) to simulate the same ride in the model. They then compare the model results to 
the measured data. They experiment with changing parameters in the model (including the PID controller settings) of the elevator to attempt to make the elevators more effective (faster without harming the people riding the elevator). The final results get reported to their manager in the form of a memo and report in which they recommend action (or not) to speed up the customer's building's elevators.

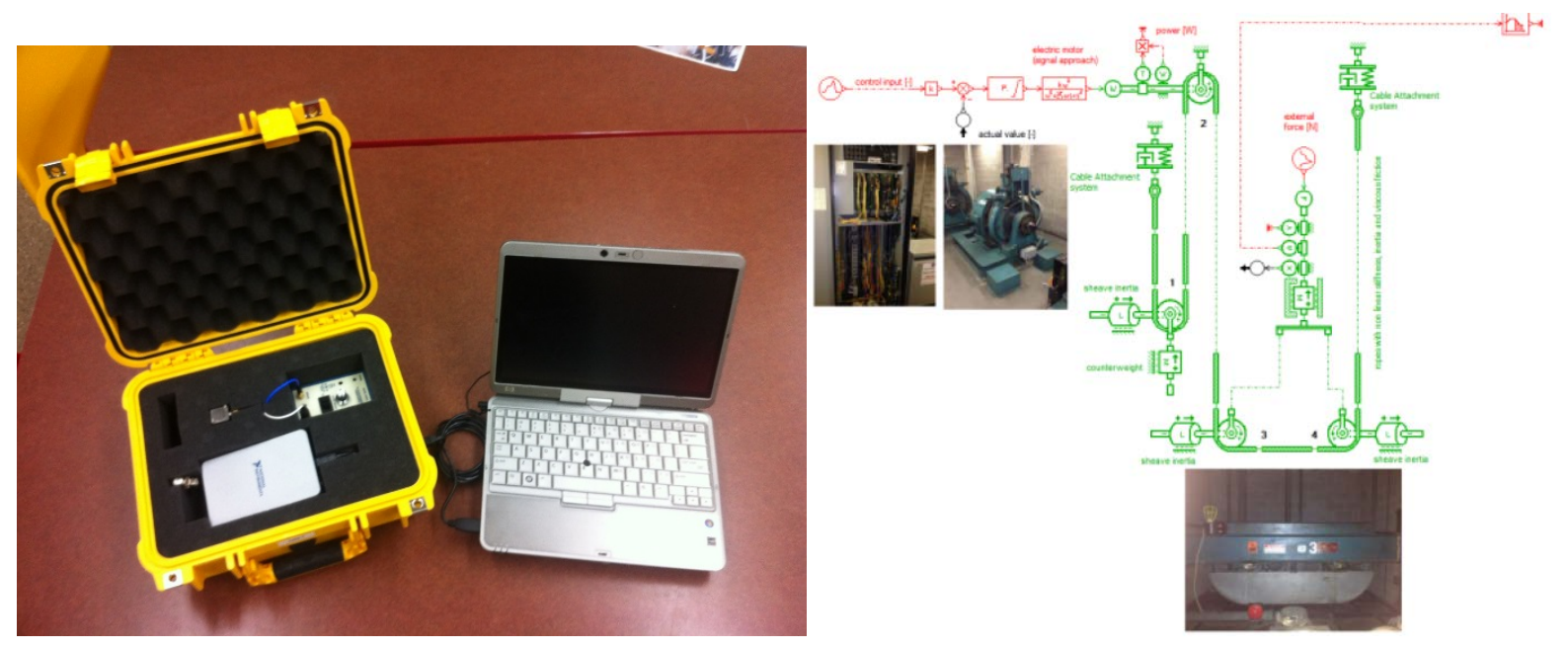

Figure 6: Accelerometer and laptop setup to measure acceleration while riding the elevators (Left) and the provided elevator model (Right).

Three weeks of bridge modeling and experiment

During this three week topic, students learn the fundamentals of Finite Element Analysis using the stiffness matrix method, model a bridge using 1D truss elements in Hyperworks FEA software. They follow tutorials in class for a concentrated load on a truss structure with rod elements and a distributed load on a truss structure with rod elements followed by the third week with a concentrated load on a truss structure with beam elements. During the third week they learn about designing one specific truss element with a factor of safety of one, to model that in the FEA software to confirm their factor of safety design and then how to design and 3D print the truss member. During the practice sessions the students build a Pratt or Howe-style truss bridge using PASCO bridge kits, load the bridges and measure the loads in four truss locations as well as the deflection in the center of the bridge (Figure 7). They apply concentrated and distributed loads and compare the results to the FEA truss models as well as the loads from hand calculations using the methods of sections or nodal equilibrium which were just covered in statics. In addition, a Matlab FEA code is provided to them that they then have to adapt to match their bridge design and compare results. This allows them to compare theoretical hand calculations, a commercial FEA package, a home-made Matlab FEA code and experimental results. During the third week, they $3 \mathrm{D}$ print their redesigned truss member, assemble it into the bridge and load the bridge while measuring load until the 3D printed truss member fails. They then compare the load to the design load and need to explain any discrepancies (due to 3D printing manufacturing process, human error, measurement error, precision, modeling assumptions, etc.). This is reported in the form of a memo and report to their engineering manager as part of a bridge redesign project. 


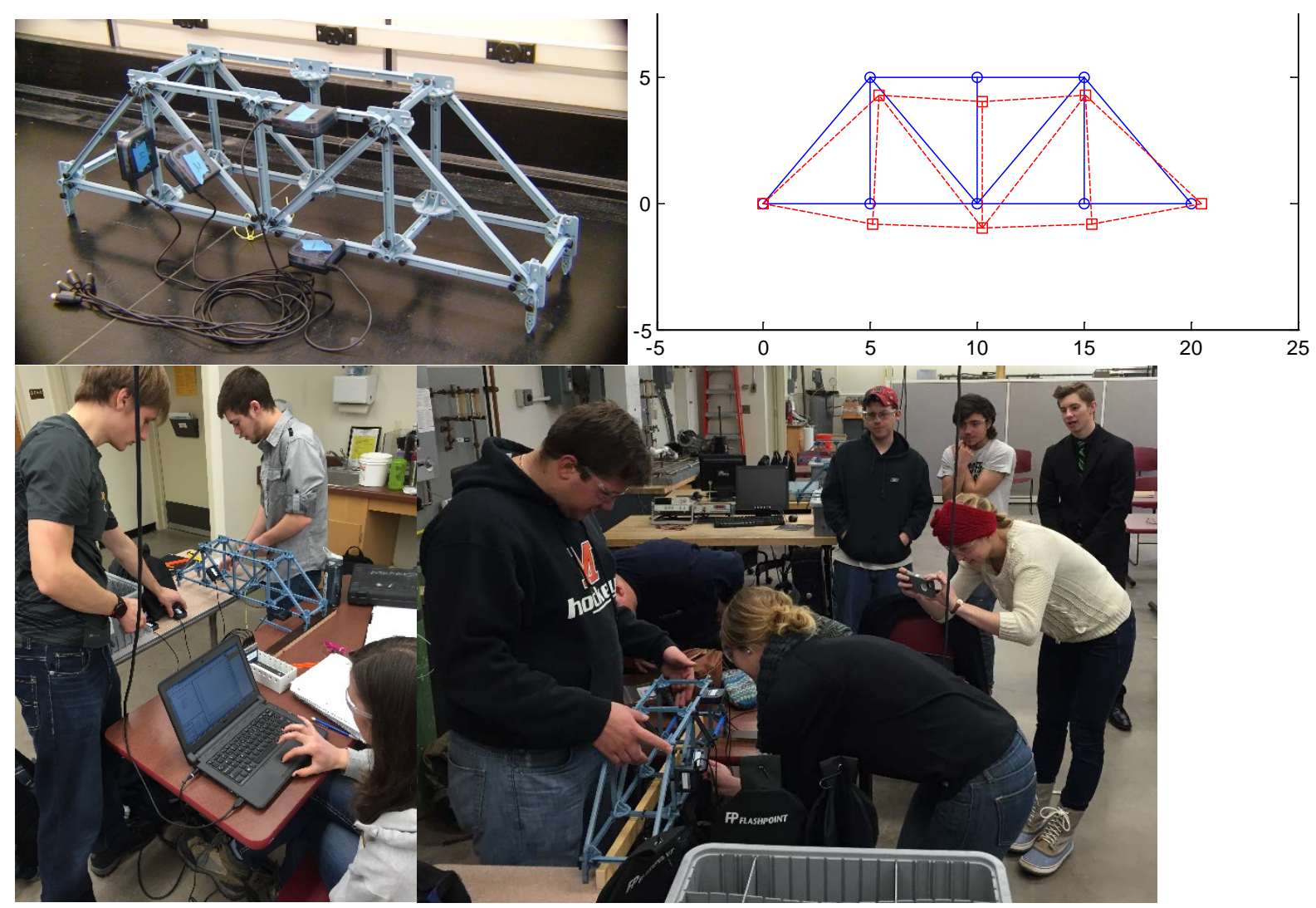

Figure 7: The Pasco bridge setup with sensors installed (Top Left); the Matlab plot of the displacements of the FEA Matlab model (Top Right); a team of students installing sensors in their bridge (Bottom Left) and a group of students loading their bridge until the 3D printed truss element fails (Bottom Right).

Two weeks of manufacturing

During the first week students learn about manufacturing using lathes. The important machine parameters such as tool speed, cutting depth, material hardness are covered in addition to different types of lathes and the use of G-code. The students then have to decode a piece of Gcode since according to the scenario the design drawings were lost in a flood but the G-code was still on the machine. They have to produce a sketch to scale and with dimensions of what the part will look like. The first practice session covers machine and tool offsets and allows them to make the base of the part. During the second week, the students actually produce the top part of the chess piece (a different one every semester). They use right hand, center and left hand cutters as well as a drill and counter bore followed by hand-tapping and screwing in the magnet to hold the piece to any fridge or magnetic chess board. They report their results in a memo and short report to their engineering manager.

One week of final presentations and portfolio preparation

The final lecture explains how professional presentations should be performed and what not to do. An example is performed of how to build a presentation starting with an empty PowerPoint presentation. It also covers the final assignment which consists of a portfolio of student work (four of their assignments of this class) prefaced by a one page memo describing why they picked those four reports, what they learned, and what classes helped them the most during this 
class. This facilitates reflection on their learning and relationships between topics and other classes. During the practice session each group delivers a 12-minute presentation on one of the team reports they had to turn in this semester. They then answer questions and evaluate all the other teams (4 other teams typically in one practice session).

\section{Scenario based}

The assignments during the course have been designed around real work scenarios. When they graduate they do not write for instructors or professors, they write for colleagues, managers, clients or other stakeholders and concerns the format as well as the content. The assignments are split between individual and team work so that each student has to learn all the skills (e.g. software) and report on it on their own followed by team reports where they then apply those skills in a team setting. This is done so no student can get by in a group without learning all the skills.

\section{Lecture \& practice session}

The one hour per week lecture is done in groups of 60-65 (ALC room seating limit) and the practice sessions (two hours per week) are run in groups of 15 with teams of 3 students (5 teams per practice session). The practice session size is determined by equipment availability and room size. Lectures are delivered by professors and the practice sessions are all done by Graduate Teaching Assistants (GTAs) except that each professor teaches one practice session to make sure all details of the practice sessions are properly developed and taught. The lecture allows the coupling between theory (from other classes and this class) and the upcoming practice session. Each lecture session also contains a quiz on the learning management system (LMS) to record attendance, understanding of concepts and to liven up the lectures.

\section{Implementation challenges}

The largest challenge were the logistics given the number of students (up to 265 per semester) and size of the classes. There was no test class due to scheduling and the initiation class therefore had 180 students. In fall 2015 it was 265 students and this number of students resulted in 4 lecture and 18 lab sections which required two parallel classes with a different sequence due to room and equipment availability. Scheduling was especially challenging during transition while the old curriculum was not phased out yet. Coordination of 265 students in two parallel classes, 5 rooms, 4 faculty and 5 GTAs for MEP-1 in combination with room usage by other courses during the three year transition period required the development of an implementation planning tool in the form of an elaborate Excel spreadsheet that could track resources and the implementation schedule for all four MEP courses for the entire department. The course coordinator's job and communication with the implementation team was crucial in preparing and coordinating materials, training faculty and GTAs, schedules and resources. Weekly coordination meetings are still held to prepare the team each week for the practice sessions and to discuss rubrics and grading expectations to facilitate grading uniformity. For initial feedback and assessment, student quizzes were given and the portfolio assignment also provided great insights besides the student evaluations of the course. Some feedback will be discussed in the following section.

\section{Successes}

As part of the standard course evaluations students are asked a set of questions. Table 3 shows the results of the available data. The data is shown in two columns to indicate how large the 
percentage of responses was in the Neutral or better category and the second column indicating the actively positive responses. Some semesters the participation in the course evaluation was around or below $50 \%$ which could skew the conclusions. It shows the students understand the goals and relevancy of the course. For most students the course was designed and organized correctly. Changes were made along the way in organization of class materials, communication to the students, and quality of GTA performance by training and monitoring progress.

As part of our assessment and continuous improvement plan for the ME Practice curriculum, we required students in MEEM 2901 to submit portfolios consisting of four assignments and a reflective essay at the end of the spring semester. The students were asked to explain why they chose those particular assignments, what courses helped them the most in MEP I, what helped their learning, what aspects of the course were least helpful, and what they would recommend to improve the course in the future.

A spring 2015 example of the result evaluation of the essays reflect changes made to MEP-1 from the fall 2014 to spring 2015 semester, demonstrating that efforts to improve issues like organization, classroom communication, and tutorials were successful to a certain extent. The essays also reveal some new concerns such as lack of training and engagement on the part of one Graduate Teaching Assistant (GTA) in particular, which had a negative effect on learning. An overview of the 108 essay responses is given here and includes some recommendations by the students on ways to improve the course further. Future analysis of all four MEP courses as well as analysis over multiple semesters will take place once sufficient data of all four MEP courses has been collected and will be presented in a future conference.

\section{Most popular assignments chosen for the portfolio}

The most popular assignments were those involving the bridge truss activities, the elevator simulation, and reverse engineering. Students said they were immediately able to see how the software and hardware used could be applied to "real-world" engineering problems. Many students still found the Bridge Truss labs frustrating (learning software, problems with IT, learning the pros and cons of 3D printing), but they liked being able to apply what they learned in statics to a project to which they could relate - bridge structure and design.

While students in the fall cited the DAQ lab as most challenging because they were presented with too much material to absorb in one class session, the revamping of that lesson was successful because few students cited it as problematic and some enjoyed the challenge of learning something entirely new.

However, the tension-testing lab continues to be incredibly difficult for many students. Nearly every student who mentioned this lab as the most challenging indicated their data was incorrect and that they did not understand what they were doing wrong. A few students suggested moving this lab after the DAQ lab so that students had experience with data acquisition before they hit the tension lab. Some students also felt this lab would be more effective as a team, rather than individual, effort. The DAQ lab is now taught before the tension lab and more feedback is given about the results determination and interpretation as well as the writing. 
Table 3: Course Evaluation results for some of the MEP-1 course sections

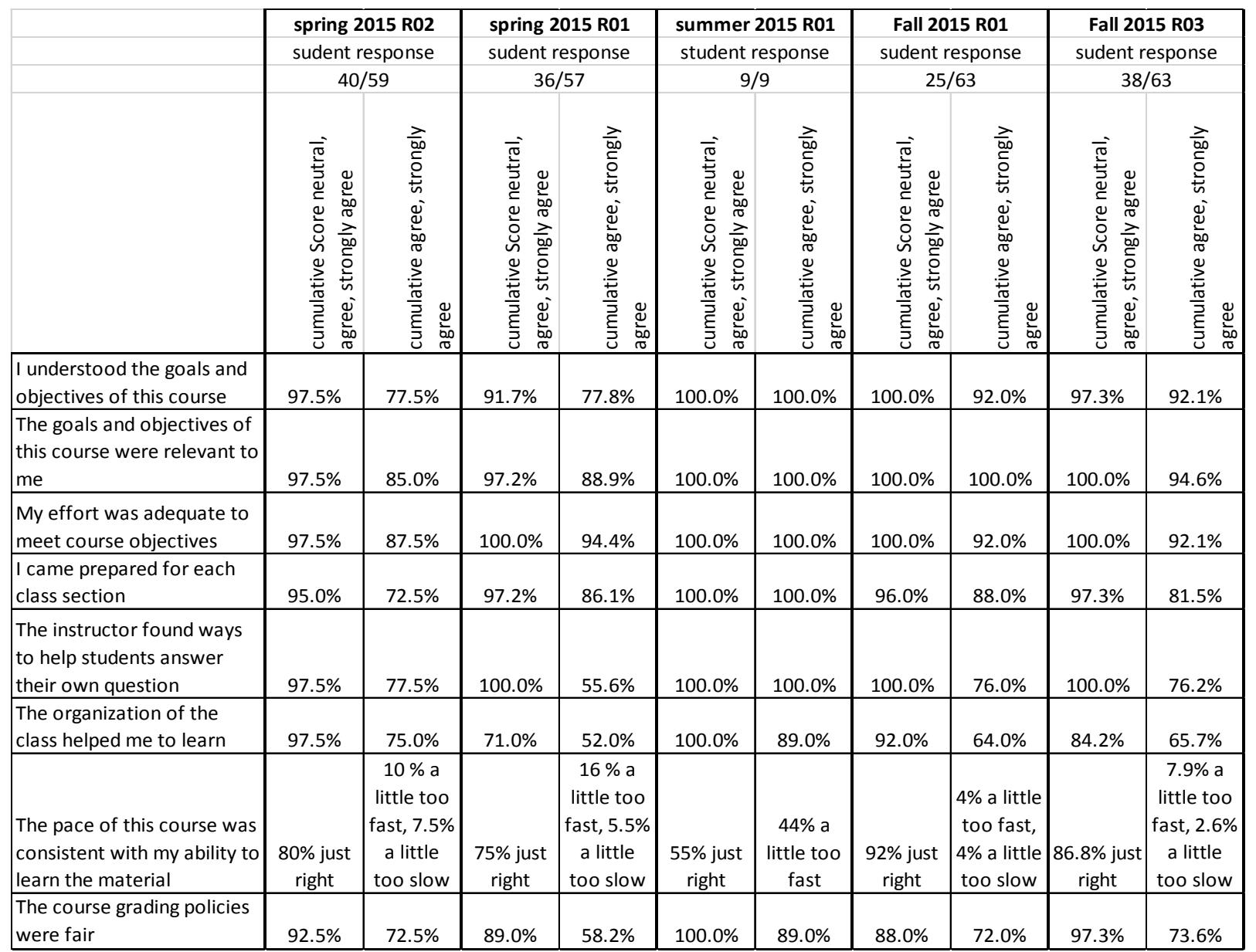

\section{Students continue to make connections between MEP 1 and other courses}

Students most often cited Intro to Material Science, Statics, and Engineering Fundamentals I and II as most helpful in MEP 1. In fact, several students felt that both Intro to Materials Science and Statics should be co-requisite for the course and at least one student mentioned that by not having taken the materials course, he was at a disadvantage for some lessons. Statics is now a corequisite for MEP-1.

\section{Aspects that helped students learn the material}

Students are enthusiastic about the course in general and understand that it is designed to introduce them to the field of mechanical engineering practice. One student said, "When I transferred into the university in the Spring 2014 semester, I was so afraid I would not be good enough for the school. Taking Mechanical Engineering Practice 1 has made me aware that, not only am I good enough, but I can excel in the Mechanical Engineering program. The amount of material I was exposed to, hand-on experience, and the confidence it gave made MEP 1 the most valuable course I have taken at the university.” 
Students mentioned a wide variety of aspects of the course that helped them learn the material and function effectively in lab:

- Their lab instructor could make or break their experience. Some instructors were cited multiple times as being helpful, insightful, and excellent evaluators.

- Very helpful are the hands-on aspect of lab and lectures such practicing simulations, modeling, 3-D printing. A student stated; "When the lecture before each week's lab incorporated a walk through or explanation of what we are going to be doing in lab, I feel the labs were easier to grasp. A short demo or breakdown of the data we are going to be collecting really helps me understand why and what I'm doing when I do the actual lab.”

- Recording the lectures for online viewing so students can go back and watch them was mentioned often. This practice has a downside in that many students said they rarely went to lecture since they were able to get everything they "needed to know for lab" by watching the videos. Students suggested incorporating more "practice" into the lectures and forcing students to use the computers as well as making attendance mandatory to encourage more people to come to class.

- Providing lab instructions several days in advance helped students be better prepared once they stepped into lab.

- Students appreciated having a mix of individual and group assignments because the individual assignments forced them to learn the material on their own and the group assignments forced them to collaborate and be open to other interpretations of instructions and lecture material. One student noted, "One aspect of the class that helped me learn the material was the way that the labs were done in groups, but the assignments were both group and individual. The group assignments allowed a broader range of knowledge and skills to be brought together, and the individual assignments made sure that I understood everything myself."

- Several students cited the communication modules, especially the YouTube and TED Talk videos, as helping them build their communication skills. One person specifically cited the communication quizzes as being helpful while a few other students did not.

- Having assignments targeted at a specific audience, such as engineering manager in a company, and having rubrics for certain assignments was helpful. Students liked that they could better envision the purpose of the communication if they had a specific audience, as opposed to just writing something to please the grader.

- Some students found the instructions for assignments and tutorials helpful, although many others found them confusing and urged revision.

- Some students liked the way the Learning Management System page was designed, especially the modules, but others complained they could not find relevant documents and that the communication modules did not show up in their to-do lists.

\section{Aspects of the course that did not work for students}

Several aspects did not work so well for the students, mainly the content and format of the lectures and issues with grading. Many contradictory responses were received from the students. It seems things that work for one group of students does not work for another. It is challenging with the size of the class and standardization across the many sections to customize the content. 
- Many students mentioned the lectures needed to be more engaging and seemed disconnected to the labs. There was also some disagreement about this last point as one student felt that too much time in lecture was spent on discussing the lab instructions, which were posed on Canvas. This contradiction was evident in another student's response: "What made learning the material for the class easiest was the occasional class time that got devoted to explaining what would have to be done for the next lab so I wasn't going in blind when trying to use a program or machine. On the other hand, the times it was the most difficult to learn the material was when we were given a set of instructions to follow on our own for a program such as the FEA program. The instructions were mostly clear when doing the basic examples but when trying to transition the skills learned into the lab reports, there were many problems since it was difficult to know what to include sometimes. One thing I would recommend for future classes is try to shorten up the in class example instructions and focus more heavily on what it does and why you need it."

- Most students of one particular GTA expressed concern that they learned nothing about ways to improve their writing because they received their reports back from the GTA too late for the feedback to be of much use. A few students said there was too much inconsistency in grading from one lab instructor to another.

- Some students found the course communication tools confusing, particularly the wording to lab instructions and assignments. One student said the lab instructions assumed the students knew more about the lab equipment than they did and suggested including more information about each piece of equipment and its purpose. Others found information scattered among too much different documents (no specific example provided).

Additionally, some students still struggled with the software tutorials because of lack of clarity (text not matching graphics, instructions that applied to a different version).

\section{Assessment ongoing}

Since this semester (spring 2016) MEP-4 is being implemented for the first time, assessment is ongoing in determining what is successful and what needs adjustment. The assessment study will take place over several years. The first cohort of students having taken all four MEP courses will enter senior capstone design in Fall 2016 and then an objective comparison can be made between the performance of previous curriculum students and new curriculum students regarding the new skills and application of them to open ended problems for an industry sponsored project and a real customer. This study and the results will be reported at future ASEE conferences.

\section{Conclusion}

The first MEP course has been successfully introduced into the curriculum and although it had its issues and struggles it is largely received positively by students and faculty. Continuous improvements are being made. First in organization, training and documentation and we are starting to address the lectures and activities during lectures to engage the students more, encourage participation, learning and attendance. The logistical challenges to run approximately 350 students through the course per year have been met, despite running the old and new curriculum simultaneously for two years. Faculty coordination is key in running the course as well as GTA training to give timely and detailed feedback on the students writing and technical understanding. More assessment will be done in the next few years to evaluate the new curriculum as a whole. 
1. Miller et al., "Curriculum Revision to Better Integrate Mechanical Engineering Science and Practice in the 2nd and 3rd Undergraduate Years", Proc. of the ASEE Annual Conference and Exposition, 2014.

2. Kotys-Schwartz, D., D. Knight and G. Pawlas, "First-Year and Capstone Design Projects: Is the Bookend Curriculum Approach Effective for Skill Gain?” Proc. ASEE Annual Conference and Exposition, Louisville, KY, 2010. 